\title{
Lefebvre en Barcelona: trialéctica e itinerarios industriales en Poblenou
}

\author{
Pedro Limón López \\ Sergio Claudio González García \\ Universidad Complutense de Madrid. Grupo de Investigación «Espacio y Poder» \\ pedro.limon@pdi.ucm.es \\ segonz01@ucm.es
}

\section{Resumen}

En los últimos años, la configuración de itinerarios ha sido una de las políticas urbanas más importantes en lo concerniente a los imaginarios y a las prácticas de aprendizaje de la ciudad. Así, la dimensión espacial es interiorizada como parte inextricable de la experiencia de socialización histórica del barrio. Dicho aprendizaje practicado del espacio estaría en confluencia con otros modos de aprenderlo, fundamentalmente desde una visión geométrica y representacional de este. De ese modo, mediante el análisis de la puesta en marcha de itinerarios institucionales y contraitinerarios vecinales vinculados al proceso de renovación urbana22@en el barrio barcelonés de Poblenou, a partir de la perspectiva trialéctica, este trabajo intenta mostrar cómo, en situaciones concretas, determinados espacios urbanos son reapropiados y redefinidos al servicio de diferentes agentes políticos, lo que transforma los significados del barrio, las formas de imaginar el territorio urbano y la misma concepción geográfica de la praxis política en la ciudad.

Palabras clave: trialéctica espacial; 22@; itinerarios; imaginación geográfica; barrio

Resum. Lefebvre a Barcelona: trialèctica i itineraris industrials al Poblenou

En els últims anys, la configuració d'itineraris ha estat una de les polítiques urbanes més importants pel que fa als imaginaris i a les pràctiques d'aprenentatge de la ciutat. Així, la dimensió espacial és interioritzada com una part inextricable de l'experiència de socialització històrica del barri. Aquest aprenentatge practicat de l'espai estaria en confluència amb altres maneres d'aprendre'l, fonamentalment des d'una visió geomètrica i representacional. Així, mitjançant l'anàlisi de la posada en marxa d'itineraris institucionals i contraitineraris veïnals vinculats al procés de renovació urbana 22@, al barri barceloní del Poblenou, a partir de la perspectiva trialèctica, el present treball intenta mostrar com, en situacions concretes, determinats espais urbans són reapropiats i redefinits al servei de diferents agents polítics, la qual cosa transforma els significats del barri, les maneres d'imaginar el territori urbà i la mateixa concepció geogràfica de la praxi política a la ciutat.

Paraules clau: trialèctica espacial; 22@; itineraris; imaginació geogràfica; barri 
Résumé. Lefebvre à Barcelone: Trialectique et itinéraires industriels au Poblenou

Ces dernières années, la configuration des itinéraires a été l'une des politiques urbaines les plus importantes concernant l'apprentissage et les pratiques des villes imaginaires. Ainsi, la dimension spatiale est internalisée dans le cadre inextricable de l'expérience de socialisation au sein des quartiers. Un tel apprentissage pratique de l'espace serait en confluence avec d'autres manières de l'apprendre, principalement depuis une vision géométrique et représentation de ce dernier. De cette façon, en analysant la mise en œuvre d'itinéraires et institutionnels et de contre-itinéraires dans les quartiers liés au processus de rénovation urbaine $22 @$ dans le quartier du Poblenou de Barcelone, cet article vise à montrer comment, du point de vue de trialectique de l'espace et dans des situations particulières, certains espaces urbains sont réappropriés et redéfinis au service de différentes sensibilités politiques, changeant les significations du quartier et transformant les façons d'imaginer le territoire urbain et la même conception géographique de la praxis politique dans la ville.

Mots-clés: espace trialectique; 22@; itinéraires; imagination géographique; quartier

\section{Abstract. Lefebvre in Barcelona: Trialectic and industrial routes in Poblenou}

In recent years, itineraries and urban routes have been one of the most important urban policies concerning the imaginaries and practices that depict the city. The spatial dimension is internalized as an inseparable part of the socialization experiences in the neighbourhood. This practice of the space is realized through different manners of learning, especially from a geometrical and representational view of spatial dynamics. From a trialectic perspective, this work analyses the institutional itineraries and neighbour counter-itineraries tied to the 22@ urban renovation process in Poblenou. We show how, in specific situations, some urban spaces are reappropriated and defined by different political agents, thus transforming the neighbourhood meanings, the ways in which the urban territory is imagined and the geographical conception of political praxis in the city.

Keywords: spatial trialectic; 22@; routes; geographical imagination; neighbourhood

\section{Sumario}

1. La urbanización del capital en el 22@y las reivindicaciones vecinales en Poblenou, Barcelona

2. Disputando e imaginando la ciudad: diálogos entre espacios de representación y representaciones del espacio a través de prácticas espaciales itinerantes
3. La metodología: itinerarios participativos

4. Itinerarios industriales como campos de batalla en Poblenou

5. Conclusiones: itinerarios patrimoniales y trialéctica barrial

Referencias bibliográficas 


\section{La urbanización del capital en el 22@y las reivindicaciones vecinales en Poblenou, Barcelona}

Tras la celebración de los Juegos Olímpicos de 1992, Barcelona se convirtió en un ejemplo de ciudad proyecto y de imagen urbana global (Muxí y Borja, 2003; AAVV, 2004), así como de reconfiguración de las políticas municipales y de los espacios públicos de la población (Alabart, 1998; Domingo y Bonet, 1998; UTE, 2004; Leiva et al., 2007; Yproductions, 2007; Molinero e Ysâs, 2010; Eizaguirre et al., 2012; Subirats, 2012). En este sentido, destaca el protagonismo que adquirió el barrio barcelonés de Poblenou y su transformación urbanística a lo largo de las dos últimas décadas a raíz del proyecto 22@.

Constituido en lugar central de la producción industrial barcelonesa y catalana, así como de las pugnas por la reivindicación de la memoria colectiva de barrio en torno a la contestación vecinal, Poblenou fue objeto de la reestructuración urbana desarrollada a raíz de la desindustrialización —o reconversión industrial— que tuvo lugar entre las décadas de 1970 y 1980, así como de algunos procesos de renovación urbana vinculados a la celebración de los Juegos Olímpicos de Barcelona en 1992 —fundamentalmente, la edificación de la Villa Olímpica-. Posteriormente fueron diseñándose diferentes iniciativas relacionadas con el turismo y la producción cultural, así como con la transformación de la estructura industrial anterior en formas de producción ligadas a la economía creativa y del conocimiento, donde Poblenou emergió como un espacio idóneo por la estructura fabril alrededor de la cual se erigía el barrio, así como por las múltiples formas de reivindicación de la memoria industrial barcelonesa inextricablemente unida a Poblenou como elemento indisociable de la cultura de la ciudad. En ese contexto, el proyecto 22@ emergió como una iniciativa central de los cambios sobre la planificación urbanística, en la configuración de imaginarios alrededor del espacio público urbano y, en particular, la condensación de los conflictos sobre el patrimonio representados en el despliegue de determinados itinerarios urbanos.

El22@ Barcelona es un proyecto de renovación sectorial y territorial de la mayoría de los antiguos espacios fabriles de Poblenou desarrollado en la Ciudad Condal desde el año 2000 con vocación de transformar el espacio urbano en clave de ciudad digital y del conocimiento (Oliva, 2003; Guillot, 2004). En el barrio se ha producido una zonificación basada en la creación de una nueva centralidad urbana como distrito tecnológico que resitúe Barcelona globalmente como un modelo a exportar (AAVV, 2011). Dicha iniciativa ha desatado una serie de transformaciones sobre la estructura morfológica, urbanística y económica de la ciudad (Oliva, 2003; AVV Poblenou, 2004; Alfama, 2007; Rojas et al., 2007; Casellas y Pallarès-Barberà, 2009; López et al., 2011), de las cuales han sobresalido los múltiples estudios vinculados a la promoción de espacios económicos creativos (Pareja y Pradel, 2010; Martí-Costa y Pradel, 2012), las nuevas experiencias de consumo y la creación del barrio como lugar artístico (Casellas, 2009; Valera, 2009), el análisis de procesos de patrimonialización cultural de la memoria industrial (Tatjer y Vilanova, 2002; Fernández 
y Tatjer, 2005; Checa, 2002, 2007, 2008; Tatjer, 2008; Gárate, 2011), la influencia del barrio en la nueva ciudad creativa y la generación de distritos del conocimiento (AAVV, 2011; Clark, 2011) o la centralidad de los agentes locales en la reestructuración urbana (y en la gentrificación) del barrio (Vera et al., 2009; Dot et al., 2009, 2010a: 398, 2010b, 2011, 2012; Charnock y Ribera-Fumaz, 2011: 613).

No obstante, este proyecto también fue promocionado como una continuidad de la tradición histórica productiva vinculada al barrio de Poblenou y de los conflictos existentes alrededor del patrimonio industrial, materializados tanto en términos de conflicto vecinal como de reconocimiento normativo (Tatjer y Vilanova, 2002; FAVB, 2008, 2010) ${ }^{1}$, como puede verse en la oposición de los itinerarios analizados. Ambas formas de articulación de dichos recorridos producen espacio público, lo reivindican y lo proyectan, estableciendo imaginarios de lo que se demanda y se patrimonializa como Poblenou, como espacio cotidiano barrial o como nueva espacialidad global. De ahí la pertinencia de no analizar de manera aislada dichos itinerarios, en la medida en que tales contraespacios contestarían continuamente y de forma simultánea a los discursos dominantes sobre la ciudad y el patrimonio urbano. Siguiendo los planteamientos teóricos de Lefebvre, este trabajo propone un análisis en el que dichas dinámicas no solo no se producen de forma aislada, sino que deberían tenerse en cuenta de manera coconstitutiva, en la medida en que se encuadran en procesos más amplios dentro de la producción del espacio urbano, considerando todas las dimensiones que lo constituyen —en términos de espacio concebido, percibido y vivido-, tal como se esboza a grandes rasgos en el próximo epígrafe.

Posteriormente, se desarrolla dicho estudio a partir de los datos recabados en dos itinerarios realizados en Barcelona a lo largo de distintos recorridos que encarnaban y proyectaban el patrimonio industrial de Poblenou vinculados al proyecto 22@, deteniéndose en distintos puntos considerados emblemáticos del mismo. En el primero de ellos se realizó un recorrido organizado por el Centro de Cultura Contemporánea de Barcelona, denominado «Poblenou, la ciudad reinventada», mientras el segundo consistía en una iniciativa creada desde colectivos vecinales en cooperación con algunos expertos universitarios en patrimonio industrial.

Finalmente, se discuten los resultados de la investigación y la pertinencia de la trialéctica espacial como herramienta teórica desde la que comprender y explicar la irrupción de los itinerarios como armas desde las que diferentes actores políticos producen, se apropian, imaginan y proyectan el espacio público, ya sea desde la praxis cotidiana o desde la abstracción geométrica de la representación espacial.

1. Reconocido en las modificaciones del Plan Especial de Protección del Patrimonio arquitectónico, histórico y artístico industrial de Poblenou, Plan Especial de Infraestructuras de Poblenou, Modificación del Plan General Metropolitano en el ámbito del casco antiguo del Poblenou (Ayuntamiento de Barcelona, 2010b: 18-20), 22@ Estado de ejecución (Ayuntamiento de Barcelona, 2009: 15). 


\section{Disputando e imaginando la ciudad: diálogos entre espacios de representación y representaciones del espacio a través de prácticas espaciales itinerantes}

En las últimas décadas, se ha destacado el impacto que han ejercido los procesos de regeneración urbana y los fenómenos de marketing de la ciudad sobre la reconfiguración del paisaje local y las representaciones urbanas globales (Balibrea, 2007; McNeil, 2007; Degen, 2008, 2010; Degen y García, 2008; Muñoz, 2008, 2010; Dot et al., 2010a, 2010b; González, 2011; Degen y García, 2012), vinculado a las dinámicas de turistificación, ocio y consumo cultural de los ámbitos urbanos. En especial hay que destacar el énfasis que la emergencia de la producción cultural y los procesos turísticos han hecho sobre el paisaje urbano como una forma de patrimonialización de la ciudad, que entrelaza tanto los imaginarios como los símbolos identitarios ligados al patrimonio municipal (Galindo y Sabaté, 2009: 23). Es así como puede entenderse la irrupción de los itinerarios patrimoniales y la preservación de esos símbolos de patrimonialización a través de mecanismos de planificación urbanística desarrollados por las instituciones locales en relación con múltiples fenómenos de renovación urbana, apareciendo diferentes conflictos entre los símbolos comunitarios y los procesos de acumulación (Waitt, 2000; Baer, 2006; Pendlebury et al., 2009: 350-351).

Considerando el patrimonio como una construcción colectiva que no está configurada sobre criterios objetivos, que es contingente y que conlleva efectos sociales y políticos (Viejo-Rose, 2013: 26), pretendemos señalar que los itinerarios actúan como una representación institucional o formal del espacio público y también como una forma de resistencia a los procesos y a los planes urbanos anteriormente señalados, con lo que se establece una expresión de la existencia de espacios de representación o contraespacios (Lefebvre, 1991b). Ello implica una consideración de la superficie pública que no se reduce meramente a los efectos económicos de un proceso de renovación urbana en Poblenou ni a establecer el espacio como un mero contenedor de las relaciones sociales. Dado que en este se produce una interacción constante entre su concepción, percepción y vivencia, ha de entenderse en una doble dimensión, como producto y como productor de relaciones sociales y políticas (ibidem: 73).

Siguiendo a Lefebvre (1974, 1976, 1991a, 1991b), las relaciones sociales y la estructura de producción están interrelacionadas con el espacio dentro de una compleja dialéctica socioespacial donde este es considerado un producto social vinculado a la experiencia, a las prácticas, a las relaciones y a las acciones sociales, y donde el proceso de su producción —así como las implicaciones y las intencionalidades del mismo - tiene que ser puesto de relieve, tal como sistematizó en su obra La producción del espacio (Lefebvre, 1991b)2.

2. La primera publicación de esta obra, La production de l'espace, es de 1974, pero en este artículo se va a utilizar su traducción inglesa de 1991. Recientemente la editorial Capitán Swing ha editado una versión en castellano. 
A partir de una consideración de lo social y lo espacial como elementos dialécticos y sin una relación determinista, el espacio elevaba su condición, con lo que pasaba de ser un mero contenedor o subproducto de otras relaciones sociales a considerarse una parte integrante de la naturaleza del ser humano (Soja, 1996: 71), por ello se configuró un análisis unitario del espacio que superase la fragmentación y la división entre lo mental y lo físico desde la que se había venido observando (Hiernaux-Nicolás, 2004: 14; Lefebvre, 1991b). Por ello, un análisis reduccionista que considera el espacio como una pura abstracción geométrica sin contacto con la realidad o como velo de la misma ha de ser desplazado por una teoría unitaria que refleje la interacción constante entre el espacio mental físico y social, lo cual permite descifrar, analizar y leer el significado del espacio social que envuelve su experiencia y su vivencia, en aras a entender las profundas relaciones y las contradicciones de los elementos que lo componen (Lefebvre, 1991b: 14-17). Así, el espacio debe ser considerado un producto social vinculado a la experiencia, a las acciones y a las relaciones, lo que pone el proceso de su producción en el foco del análisis (Elden, 2004: 175).

El intento por superar este reduccionismo, junto con la importancia que empieza a cobrar la experiencia cotidiana del espacio, lleva a Lefebvre a concretar su unidad de análisis en una tríada formada por lo concebido, lo percibido y lo vivido. Autores posteriores como Soja han dado más importancia a la separación entre estos tres momentos, al hablar de una clasificación basada en los conceptos de primer, segundo y tercer espacio, concediendo una importancia emancipadora a este último (Soja, 1996: 25). Esta importancia de la vida cotidiana, donde los itinerarios permiten reflejar los lugares más vinculados con la misma y que se relacionan con lo emotivo, lo propio y lo simbólico, es fundamental para expandir la alienación y los efectos de la producción económica más allá del ámbito laboral, hasta llegar a las zonas más íntimas de la existencia humana, en este caso los barrios de las ciudades (Goonewardena, 2008: 128).

El espacio concebido es el ámbito de la proyección y la planificación propias de técnicos, urbanistas y tecnócratas, está vinculado a la imaginación y a la proyección mental y es definido por Lefebvre como «representaciones del espacio» o, lo que es lo mismo:

[...] el espacio conceptualizado, propio de los científicos, planeadores, urbanistas, ingenieros sociales y tecnócratas, como un tipo particular de habilidad $\mathrm{o}$ arte con inclinaciones científicas - aquellas que identifican lo que es vivido y percibido con lo que está concebido. (Lefebvre, 1991b: 38)

Las representaciones del espacio parten de una imposición de un orden, es decir, de crear una normatividad por medio de códigos y signos que se proyectan en él. La finalidad última es la concepción de un ámbito que imponga una determinada forma de ordenarlo, leerlo y comprenderlo. Dado que en esta concepción existe un objetivo, la imposición del mismo las vincula con las relaciones de poder que buscan imponer dicha concepción y consolidar determinados discursos e imaginarios sobre el espacio. Estas representaciones 
espaciales son un elemento fundamental de configuración en el discurso, lo que influye enormemente en la articulación de imaginarios urbanos (Schmid, 2008: 37). Estas representaciones, en gran medida en forma de proyectos y planificaciones, ocultarían los conflictos sociales por medio de una trasparencia legible asentada en códigos científicos.

En segundo lugar, el espacio de lo percibido se vincularía con la práctica diaria, con el nivel de lo material y lo mesurable, aquel ámbito que el autor denomina "prácticas espaciales», las cuales están relacionadas con el mundo físico, con las rutas y los lugares específicos, con la producción y la reproducción, con actividades sociales y rutinarias que se convierten en formas tangibles de ocupar el espacio (Lefebvre, 1991b: 33). Estas prácticas permitirían la definición de un espacio como propio por medio de su utilización física, tangible y medible, lo cual posibilitaría que este fuera analizable, observable, descifrable y percibido (Hiernaux-Nicolás, 2004: 16). En su práctica diaria, cuando el ser humano se mueve, actúa, transita, crea y realiza actuaciones en el lugar físico, está apropiándose del mismo y da a la experiencia de la vida cotidiana una dimensión material, otorgándose el espacio generado y descifrando sus diferentes configuraciones (Lefebvre, 1991b: 38; Oslender, 2010: 98).

En el caso que nos ocupa, las formas de hacer visible y medible este espacio serían los itinerarios y las prácticas de señalización de las zonas de renovación urbana en Poblenou, que están condicionadas por la concepción. Es decir, estas prácticas están en una interacción constante con los discursos sobre el espacio que imponen las representaciones espaciales.

El tercer momento sería el espacio vivido, que, según esta concepción, emergería como el lugar de la resistencia en la producción del espacio. Los grupos, en su devenir temporal, generarían significados, sentidos, símbolos en su vida cotidiana que interactuarían y afectarían a su experiencia del ámbito concreto, lo que daría lugar a esta vivencia o «espacios de representación», a saber:

[...] el espacio como se vive directamente a través de sus vínculos simbólicos e imaginarios, y por tanto el espacio según quienes lo habitan y lo usan, aunque también de artistas y, quizás, de algunos artistas, escritores y filósofos que describen y aspiran nada más que a describir el espacio. (Lefebvre, 1991b: 39)

Estos «espacios de representación» derivan de una determinada forma de mirar la realidad fundamentada sobre códigos y símbolos vinculados a la identidad, a las imágenes, a los paisajes y a los significados interiorizados en el espacio habitado a lo largo del tiempo, por ejemplo, en el barrio de Poblenou. Se configuran en la vida social más ligada a la experiencia personal y en la memoria colectiva del grupo, en la historia como grupo y como individuos pertenecientes a ese grupo (Lefebvre, 1991b: 41). Un third space para Soja que va a permitir la contradicción y la liberación, que es conocible, múltiple y que permite la existencia de «otros» espacios (Benach y Albet, 2010: 206).

Estos espacios de representación no aparecen de forma aislada, sino dentro de la relación trialéctica de interacción conflictual con lo concebido e influyen- 
do en la práctica social (Lefebvre, 1991b: 41). Un barrio, sus calles, sus plazas, sus comercios y sus lugares convocantes forman parte de los centros afectivos o del núcleo de este ámbito vivido. Estos lugares, sus símbolos y los significados que se les atribuyen dibujan un espacio habitado propio que interactúa con las prácticas espaciales y que se relaciona dialécticamente con las representaciones espaciales, articulándose como un contraespacio de aquellas. Por ello, aparece la disputa entre la concepción técnica que busca crear una mirada normativa sobre el espacio desde un barniz de aspiración neutral y un espacio vivido que confiere significados propios a un lugar experimentado día a día, conflicto que se hace tangible mediante las prácticas espaciales, que, en este caso, aparecerían condensadas en los itinerarios alrededor de Poblenou.

Toda esta formulación teórica nos debe llevar a comprender que la producción del espacio no es neutral, dado que está atravesada por relaciones de poder y es política (Oslender, 2002: 1). La disputa entre un espacio que busca establecer una normatividad y un contraespacio evidencia un conflicto articulado en torno a concretas correlaciones de fuerzas. Las representaciones del espacio son un reflejo de las relaciones de poder, refuerzan una hegemonía de clase y reproducen estas relaciones por medio de discursos técnicos y abstractos sobre un lugar determinado. De esta forma, y vinculados al proyecto $22 @$, aparecen tanto representaciones del espacio como espacios de representación barrial que se vertebran a través de las rutas aquí estudiadas. Así, la articulación de distintos itinerarios no es tan solo la discrepancia entre mecanismos múltiples de proyectar el paisaje urbano, ni la mera expresión de un conflicto entre distintas formas de representar el patrimonio industrial, sino que constituye una herramienta esencial desde la que observar la pugna motorizada por la imaginación geográfica ${ }^{3}$ y por la apropiación del espacio público en Poblenou y en Barcelona. De esta manera, los itinerarios se convierten en lugares de resistencia que permiten hacer evidentes formas distintas de concebir la ciudad en una lucha contra la normatividad impuesta por los proyectos urbanos institucionales. En la medida en que los itinerarios constituyen el momento y el lugar en que las representaciones del espacio y los espacios de representación se encuentran en su reivindicación por los lugares patrimoniales y por la ciudad misma, la trialéctica espacial deviene obligación en el análisis aquí propuesto. Por lo tanto, estas formas de impugnación se convierten en expresiones del derecho a la ciudad ante los procesos de renovación urbana que convierten a determinados espacios de la ciudad - y al conjunto de ella - en espacios de consumo orientados a los procesos de acumulación capitalista, con todos los procesos derivados de las dinámicas de gentrificación que generan y contra las que aparecen resistencias sociales, en este caso, los itinerarios vecinales.

3. La imaginación geográfica es la «sensibilidad hacia la importancia del lugar, el espacio y el paisaje en la formación y conducta de la vida social [...], algo que permite a los individuos reconocer la función del espacio y del lugar en su propia vida, en relación con los espacios que ven a su alrededor, identificar cómo las transacciones entre individuos y entre organizaciones están afectadas por el espacio que las separa [...] juzgar la relevancia de acontecimientos en otros espacios [...] modelar y utilizar el espacio de forma creativa, y apreciar el significado de las formas espaciales creadas por otros» (Johnston et al., 2000: 321). 


\section{La metodología: itinerarios participativos}

En la medida en que existen conexiones entre los edificios, los recorridos cotidianos y la iconografía del paisaje urbano, la socialización espacial vinculada al barrio está conectada a una forma de producción cultural que representa una manera de ver el mundo (Tuan, 1977). Destaca, en este sentido, la capacidad performativa que los «actos de visionado» tienen en la reinscripción de la imaginación geográfica y las representaciones, en la medida en que produce el imaginario que supuestamente preexiste a esa representación (Rose, 2014: 10-11).

Por ello, para analizar cómo se desarrolla la trialéctica a través de los itinerarios industriales en Poblenou, se ha seguido una metodología basada en la observación participante a lo largo de los recorridos propuestos en los dos aquí comparados. En la medida en que se trata de significados, elementos simbólicos, experiencias subjetivas, imaginación y representaciones políticas vinculadas a procesos sistemáticos y cuyos contextos son esenciales (Marsh y Stoker, 1997: 145 s.), el uso de esta metodología es pertinente en la contrastación de los objetivos planteados, además de combinarse con otras fuentes de información adicionales ${ }^{4}$.

Dicho trabajo de observación se realizó a lo largo de dos itinerarios desplegados en Poblenou conforme a lo que se denominaba «memoria industrial» del barrio en el intervalo de una semana de estudio durante el mes de mayo de 2013 — se realizaron el 4 y el 11 de mayo de 2013 — 5 . Mientras en el primer caso se organizaron dos grupos, uno en castellano (con 14 personas) y otro en catalán (con 19 personas), con una mayoría de asistencia turística, estudiantes y personas de la tercera edad, en el segundo la afluencia fue minoritaria (5 personas) y con predominancia de gente joven y próxima al activismo universitario y vecinal del barrio.

El primer recorrido se incluía dentro de la exposición «Poblenou, la ciudad reinventada», organizada por el Centro de Cultura Contemporánea de Barcelona, y es uno de los itinerarios fundamentales de este tipo, a lo largo del cual se recorren lugares de resignificación y rememoración del pasado barrial — desde el punto de vista institucional—, así como zonas de reestructuración industrial y turística barrial, siguiendo los distintos emplazamientos

4. Con el fin de aportar cierto equilibrio o alternativa de validación, así como contraste, transparencia y validez en la investigación geográfica (Hay, 2010: 348), se combina la observación participante con el análisis de fuentes primarias de incidencia política, especialmente leyes y normativas vinculadas a la planificación urbanística y la reestructuración del barrio analizado, fundamentalmente a partir del proceso de gentrificación configurado desde 1992, así como con la realización de entrevistas a informantes clave en la movilización barrial. Los análisis desarrollados sobre el material empírico, tanto en el normativo como en la observación participante, se han hecho siguiendo el análisis cualitativo de contenido discursivo y las líneas maestras metodológicas del análisis crítico del discurso (Chouliaraki y Fairclough, 1999, 2000; Howarth, 2005), cuyo objetivo «se centra en la idea de que todos los objetos y prácticas tienen un significado [...], contextual, relacional y constituido por un orden que es subvertido" (Howarth, 2005: 39).

5. Véase en <http://www.cccb.org/es/itinerari-el_poblenou_la_ciudad_reinventada-35276> y en <http://barcelonaapie.wordpress.com/category/recorridos/>. 
representativos de la memoria vecinal subsumida en el patrimonio industrial. El recorrido en sí se detiene en puntos concretos en los que se realizan varias paradas en que se van destacando diferentes aspectos de dichos lugares y de la evolución de la ruta. El segundo de los itinerarios era de alguna forma un contrapunto al primero, y en este se realizó un recorrido organizado desde asociaciones vecinales de Poblenou en cooperación con expertos académicos en patrimonio industrial, que se articuló por oposición y contestación al anterior, vertebrado a partir de un sentido diferente de la imaginación geográfico-patrimonial de Poblenou y de los referentes sobre los usos del espacio público, más ligado a la memoria local como barrio de pescadores y de movilización social.

\section{Itinerarios industriales como campos de batalla en Poblenou}

Poblenou es un barrio administrativo del distrito barcelonés de Sant Martí, situado al sureste del municipio de Barcelona y colindante con el mar Mediterráneo ${ }^{6}$. Esta zona constituyó un eje histórico en la producción industrial barcelonesa y catalana, y ha sido uno de los núcleos de la reestructuración económica y territorial de la ciudad, así como un lugar de continua reivindicación y contestación vecinal en torno al patrimonio industrial ${ }^{7}$.

A pesar de las discrepancias existentes en torno a la memoria industrial y a los usos que podían darse al reconocimiento patrimonial de la misma, tanto los planes estratégicos del sector cultural de Barcelona (en 1999 y 2006) como el Plan de Protección del Patrimonio Industrial de Poblenou y las modificaciones del Plan General Metropolitano vinculadas a este (Ayuntamiento de Barcelona, 2000, 2010a), evidenciaron la consideración institucional de la influencia de los barrios y de los distritos industriales en la memoria de la ciudad y en la creación de imágenes globales de la misma, donde Poblenou aparece con un

6. El distrito de Sant Martí cuenta con las divisiones administrativas barriales de Poblenou, Camp de l'Arpa del Clot, Clot, Parc i Llacuna del Poblenou, Vila Olímpica del Poblenou, Diagonal Mar i Front Maritim del Poblenou, el Besòs y el Maresme, Provençals del Poblenou, Sant Martí de Provençals y La Verneda i la Pau. Véanse las figuras 1 y 2, y también <http://w110. bcn.cat/portal/site/SantMarti/menuitem.05848ae0b20f8a9a2d852d85a2ef8a0c/?vgnextoid= a6ce4dc8c633a210VgnVCM10000074fea8c0RCRD\&vgnextchannel=a6ce4dc8c633a210V gnVCM10000074fea8c0RCRD\&lang=es_ES>.

7. Cuando, a partir del Plan de Renovación de Áreas Industriales de Barcelona, se dio lugar a la desindustrialización y a la reestructuración que implicaba una renovación de los barrios industriales históricos de la ciudad, surgieron múltiples movimientos vecinales reivindicando los empleos en las fábricas de Poblenou e iniciando un debate sobre el patrimonio industrial con las instituciones que ha permanecido en la agenda política hasta hoy en día (Clarós, 2005; Checa, 2007, 2008; Casellas et al., 2010, 2012). La movilización vecinal estableció un nexo entre el barrio, la fábrica y la memoria vecinal de Poblenou que se ha mantenido a lo largo de décadas (Marrero, 2003; Martí-Costa y Bonet, 2008; Bordetas, 2009, 2010) y ha dado lugar a disputas continuas sobre la legitimidad del espacio social y político de referencia vinculado a la memoria industrial, constituidas entre actores institucionales que intentaban reconstruir esa memoria en torno a la ciudad en su conjunto y la actuación vecinal que reivindicaban Poblenou como núcleo de esa memoria industrial barcelonesa. 
Figura 1. Mapa del distrito de Sant Martí por barrios

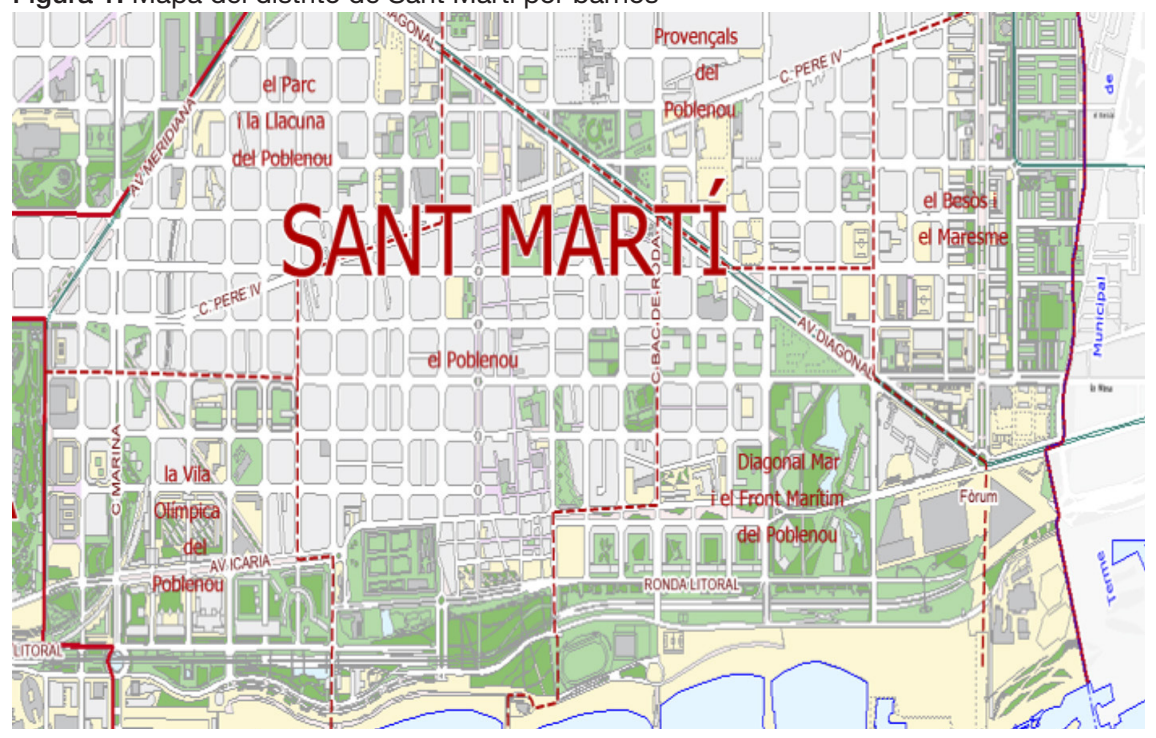

Fuente: Ayuntamiento de Barcelona.

protagonismo central, especialmente vinculado a las industrias creativas y del conocimiento.

Así es como puede entenderse la implementación del proyecto 22@ por parte del Ayuntamiento de Barcelona como un nuevo modelo de ciudad basado en un proyecto de transformación social, económica y urbana que apela a la historia de Poblenou como núcleo de producción de la ciudad (Ayuntamiento de Barcelona, 2005, 2008, 2009, 2010b, 2012; Piqué, 2008: 239), y en el que han intervenido múltiples agentes que han sido reconocidos como actores importantes en el proceso. Por una parte porque, teniendo en cuenta que la reconversión industrial barcelonesa se consideraba algo necesario e inevitable, esta iniciativa suponía conservar un tejido productivo en el barrio que, de haberse dado otras dinámicas, quizás no habría sido posible y la reconversión industrial habría tenido consecuencias mucho más negativas para el lugar, tanto en cuanto a las actividades económicas como a la degradación urbana y a los desplazamientos demográficos masivos. Por otra parte, la transformación de la industria anterior en actividades tecnológicas es vista también como una renovación de la trama urbana y la introducción de nuevas iniciativas sociales anteriormente situadas en otras partes de la ciudad, fundamentalmente alrededor del consumo, el ocio y actividades turísticas, lo que ha modificado las dinámicas sociales del barrio $\mathrm{y}$, por ende, ha sido considerado una reestructuración urbana hasta cierto punto no solo necesaria, sino también beneficiosa para Poblenou. El conflicto se produce cuando se genera una oposición entre la redefinición territorial que implica el 22@ a partir de usos de ocio y el espacio 
público o de cartografías oficiales y reconocimientos normativos diversos ${ }^{8}$, por un lado, y el mapeo producido "desde abajo» en torno a lo que se considera patrimonio industrial vecinal, por otro, diatriba que es plasmada en la oposición de los itinerarios desplegados.

La pugna por definir el espacio barrial en función del patrimonio industrial es una de las principales contiendas desarrolladas alrededor de este lugar. Siguiendo esta línea, en los últimos años diferentes actores políticos han recorrido a la realización de itinerarios, con el fin de mostrar dónde se encuentra el mismo y qué zonas incluye. Actualmente, el proyecto 22@ ha instado, mediante instituciones y asociaciones vecinales, al despliegue de itinerarios que recorren los lugares pretendidamente simbólicos no solo de un recorrido barrial, sino también de los imaginarios y representaciones del espacio de Poblenou. Efectivamente, realizar un itinerario de manera recurrente, determinar ciertas paradas en el mismo (a costa de otros lugares), agruparse alrededor de unas callejuelas para organizar unas fiestas o proyectar un mapa son técnicas que obedecen a diferentes formas de contestación, aunque convergen en la capacidad que adscriben al territorio para comunicar determinadas demandas o para difundirse más rápidamente por su capacidad sobre los imaginarios políticos y la imaginación geográfica. Así, los itinerarios y las rutas alrededor de reivindicaciones patrimoniales se convierten en las prácticas espaciales mediante las cuales las representaciones del espacio y los espacios de representación se encuentran y pugnan en la producción del espacio urbano en Poblenou. Con fines didácticos, utilizamos dos itinerarios como condensación de ese conflicto entre las «representaciones del espacio», articuladas desde las instituciones municipales, y los «espacios de representación», estatuidos por la contestación vecinal.

\subsection{Representaciones del espacio de Poblenou}

El primer itinerario realizado se hizo siguiendo el mapeado propuesto por el Centro de Cultura Contemporánea de Barcelona en torno a la exposición «Poblenou, la ciudad reinventada», configurada fundamentalmente en base a espacios de renovación industrial y turística urbana, deteniéndose en puntos concretos que iban destacando diferentes aspectos de los lugares y la evolución histórica local a través de la ruta, como se muestra a continuación.

La primera parada fue Can Saladrigas (figura 2), punto de inicio del recorrido y de la narración acerca de la importancia histórica "extramuros» desde 1714, del siglo XIX y de la industria del lugar, y por qué Poblenou se convirtió rápidamente en el gran núcleo industrial de Barcelona gracias al acceso al agua, al hábitat disponible o al paso del ferrocarril a través del barrio. Se muestra

8. En este caso, los artículos 1, 2 y 6 del Plan especial de establecimientos de concurrencia pública, hostelería y otros servicios del distrito de Sant Martí (aprobado el 21 de julio de 2006) establecía este tipo de imperativos de uso y zonificación del ocio, mientras que los artículos 4.2.5.3 y 4.2.5.4 de la misma norma establecían reconocer las actividades populares, aunque no de forma autoorganizada ni articuladas libremente. 
Figura 2. Can Saladrigas

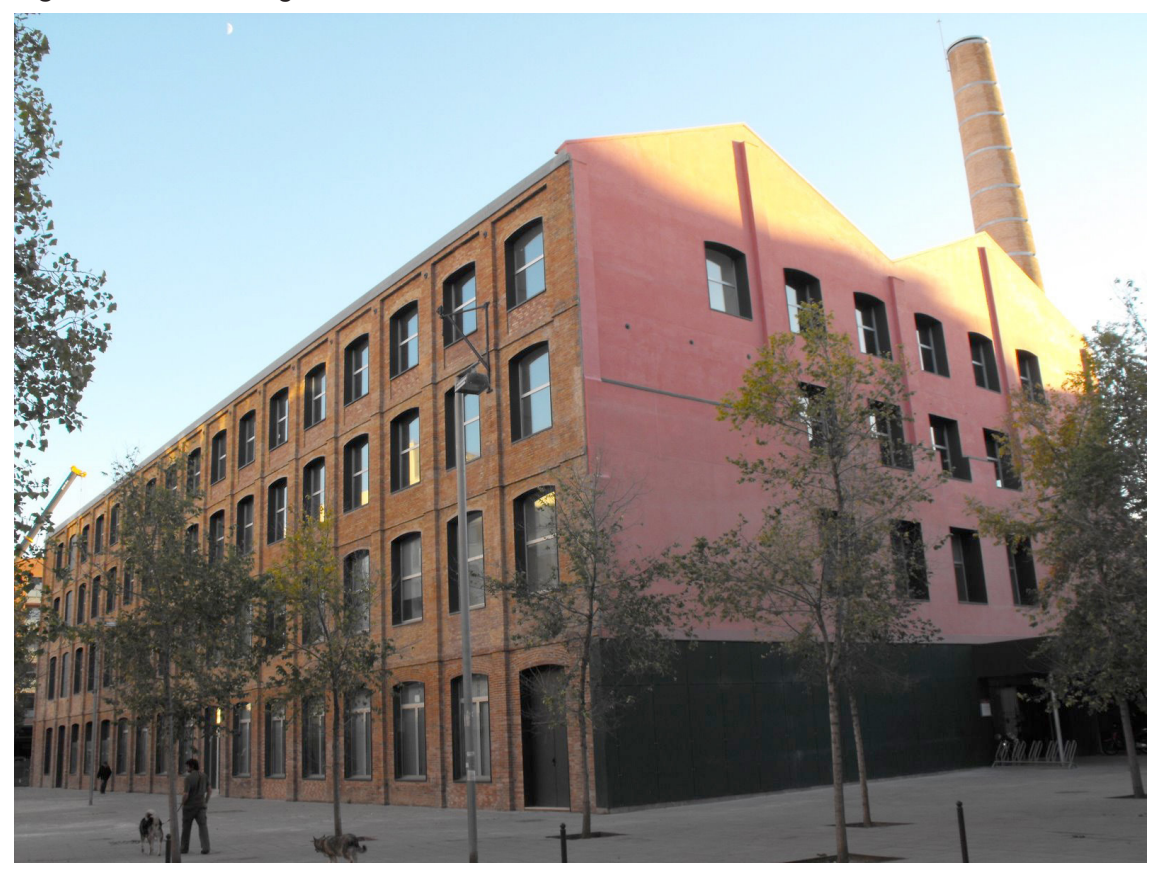

Fuente: <http://chimevapor.wordpress.com/2008/12/29/can-saladrigas-nuevo-uso/>.

cómo Can Saladrigas es un ejemplo idóneo de las casas fábricas (adyacentes) y se señala la importancia histórica de las reivindicaciones vecinales en torno al lugar y cómo se llevaron a cabo dichas demandas. No en vano, actualmente el edificio alberga la biblioteca oficial del barrio (Biblioteca Manuel Arranz) y era el lugar donde se iba a ubicar el Archivo Histórico de Poblenou. También allí se encuentra el Centro de Imaginería Festiva de Poblenou, que fue restaurado dentro del Plan de protección del patrimonio arquitectónico e industrial de Poblenou. Además, muchas de las convocatorias de las asambleas vecinales se producen en dicho lugar?.

Posteriormente nos dirigimos al mercado de Poblenou, mostrado como un nodo y un elemento físico de la identificación y de la interacción barrial frente al mercado de El Clot, además de una prueba de la importancia de la industria del hierro y la siderurgia por encima de la del textil. Desde ahí seguimos por la rambla de Poblenou (antigua calle del Triomf), enfatizándose en las dinámicas de la playa a la montaña y en la apertura de la rambla al mar. La siguiente parada es la plaza del Doctor Trueta con la calle Llacuna: se hace

9. Ver <http://www.elpoblenou.cat/index.php/actualitat-del-barri/rambla-del-poblenou/505assemblea-oberta-fem-rambla $>$. 
Figura 3. Can Gil i Vell tras la restauración

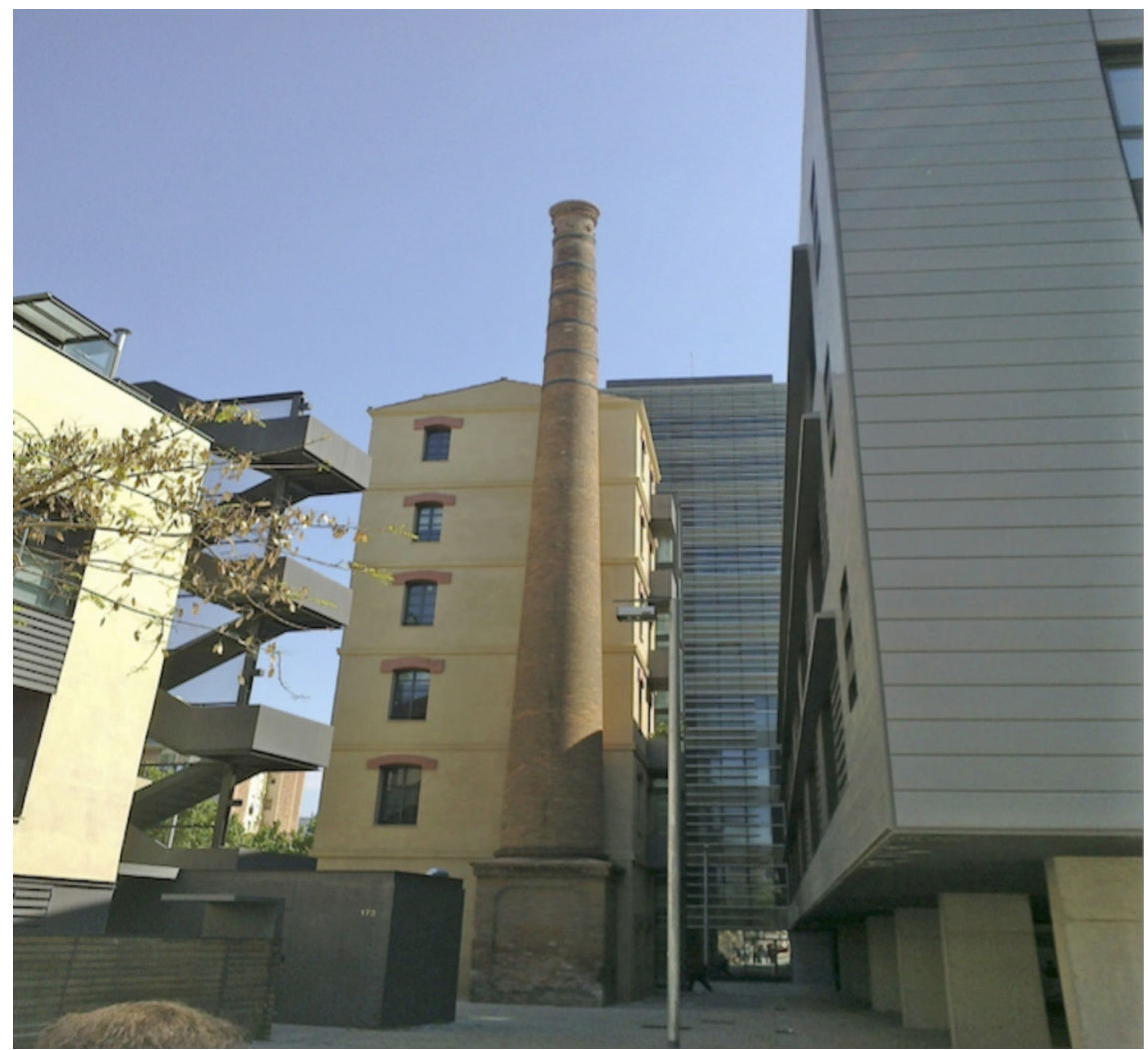

Fuente: autores.

mención al cementerio de Poblenou como un camposanto moderno y una visita recomendable y asidua de Barcelona. Además, se destaca que el itinerario se dirige hacia el inicio del 22@, un proyecto pensado a largo plazo, entre 20 y 30 años, como «nuevo barrio central en la ciudad». En la misma calle del Doctor Trueta destaca el ateneo recuperado de la Flor de Maig, que ha pasado de ser una cooperativa de consumo histórica a vincularse al Poblenou como cooperativa de ayuda al barrio.

El siguiente alto en el camino es la antigua fábrica harinera Can Gil i Vell (figura 3), donde resalta la reconversión producida por el 22@, así como sus usos mixtos (viviendas, hoteles y oficinas) y la diversificación de su utilización espacial. Se hace mención a la arquitectura, al baremo de qué era patrimonio histórico importante para el barrio, reconstruyendo parte del legado industrial —entendido como patrimonio arquitectónico-. Además, se advierte que nos encontramos en el antiguo barrio de La Plata, donde, ante la falta de restauración, recuerdos o monumentos que lo rememoren, los vecinos reconstruyeron 
por su cuenta la memoria histórica poniendo una placa conmemorativa en la plaza del barrio de La Plata.

Los destinos posteriores constituyen dos ejemplos de economía creativa dentro de la renovación de la zona. La parada comienza en el pasaje Mas de Roda, que es destacado como ejemplo de smart city debido a las farolas inteligentes, los bancos unipersonales o los cargadores para coches eléctricos y las señales de tráfico como arte popular. Después seguimos hacia la calle Llull hasta el Vapor Llull, destacado como un símbolo del 22@, puesto que evolucionaría de ser una planta química a hacer también ingeniería de materiales y pasaría de construir coches a diseñarlos ${ }^{10}$, lo que enfatiza el carácter tecnológico del distrito y su vínculo con la renovación urbana de la avenida de la Diagonal, la plaza de las Glorias o la estación de la Sagrera.

A continuación, el itinerario pasa por dos lugares emblemáticos por su antigüedad e importancia económica en el barrio, como son la antigua fábrica de harinas La Asunción, en la calle Roc Boronat, y Can Culleretes. En el primer caso se encuentra Private Space, un centro de artistas y una imprenta para autoproducción. En ese momento se nombra Hangar, situado al norte de la Diagonal, como ejemplo de autoproducción artística, aunque no se recorre su nave. En el segundo caso se destaca que el derribo de esta antigua fábrica de cubiertos dejó un solar frente a un establecimiento hotelero llamado Holiday Inn y que se habilitaron espacios para oficinas, la escuela Llacuna y viviendas de protección oficial.

Posteriormente nos detenemos en Can Framis, en los jardines Miquel Martí i Pol. Se trata de una isleta en la Fundación Vila Casas donde se levanta el Museo Can Framis y se ve el antiguo Ca l'Aranyó, donde también se encuentra el campus de audiovisuales de la Universidad Pompeu Fabra y exposiciones de arte contemporáneo catalán (figura 4).

Los últimos elementos del itinerario son los bloques de alta tecnología directamente vinculados al 22@. En primer lugar, se detalla el Edificio MediaTIC, diseñado por Enric Ruiz Geli, donde se hace alusión a su carácter de icono arquitectónico de las nuevas tecnologías, una construcción inteligente que aísla del calor y del frío. En su interior se alberga el Cibernàrium de Barcelona Activa, un centro de capacidad tecnológica. Además, enfrente se encuentra el edificio de Indra, una construcción invisible al radar por estar construida con tecnología militar. Posteriormente se muestra el Instituto de Formación Continua de la Universidad de Barcelona, situado frente al generador de Districlima, en la calle Ciutat de Granada. Asimismo, está inserto entre varios elementos emblemáticos, como la Torre Agbar de

10. Es significativo que este fuese el ejemplo utilizado para explicar el proyecto 22@ como un cambio en el carácter del suelo industrial, pasando de la calificación 22a del Plan General Metropolitano de 1976 a la calificación 22@ del área de Poblenou, insistiendo en un relato acerca del reto que supone el proyecto de cara a renovar el barrio a partir de nuevos usos industriales, encabezado por las nuevas TIC, el sector energético y los asentamientos renovados de la plaza de las Glorias y la avenida Diagonal. 
Figura 4. Fundación Vila Casas en Can Fabra

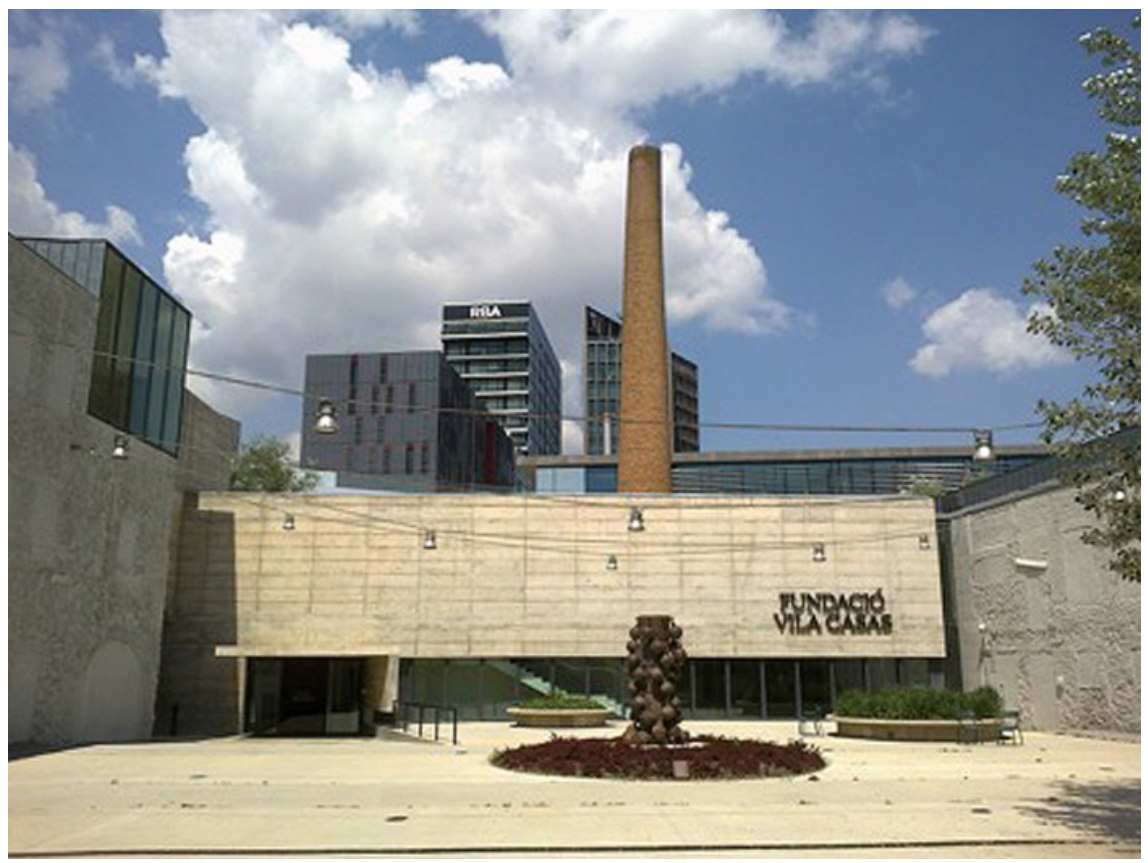

Fuente: autores.

Figura 5. Fotografía aérea por satélite de los límites territoriales reconocidos a Poblenou (en blanco el trazado del proyecto 22@)

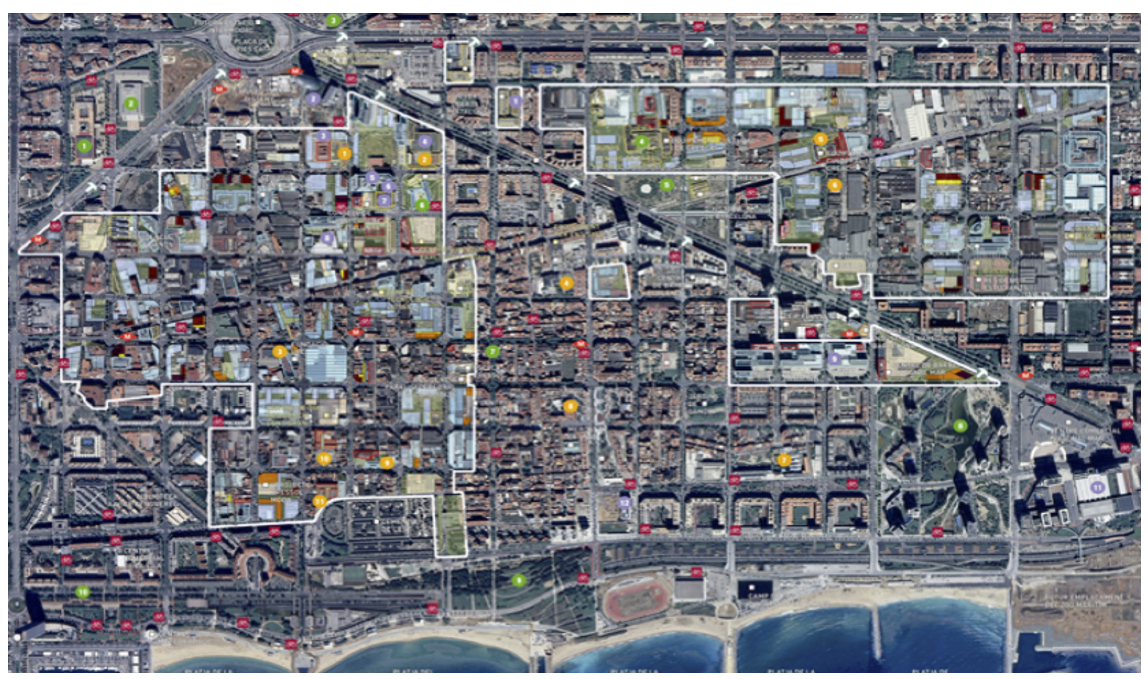

Fuente: Ayuntamiento de Barcelona. 
Jean Nouvel, la antigua fábrica Hispano-Olivetti y los edificios diseñados por Chipperfield.

El recorrido finaliza cuando se llega a la avenida de la Diagonal por la calle Ciutat de Granada, pasando junto al Museo del Diseño Urbano, proyectado por Oriol Bohigas, la Comisión del Mercado de Telecomunicaciones y la apertura de la Diagonal. Al final del itinerario, el guía explica que el recorrido escogido vincula de forma explícita el proyecto 22@ con la memoria industrial local, cuyas transformaciones pretenden crear otro nuevo centro urbano que descongestione y descentralice la actividad situada en torno al Paseo de Gracia, al igual que se está haciendo con la rambla del Raval o la avenida del Paralelo.

\subsection{Espacios de representación desde Poblenou}

El segundo recorrido se hizo siguiendo el diseño organizado a iniciativa vecinal, en cooperación con expertos académicos en patrimonio industrial y como contestación al itinerario anterior. Comienza en la estación del tranvía de Pere IV. Posteriormente, encontramos Can Jaumandreu, en la calle del Perú, edificio restaurado y dedicado en estos momentos a la renovación del arte y a los medios audiovisuales y elemento central en las demandas vecinales por el reconocimiento del patrimonio del barrio. El itinerario continúa en Can Ricart, punto emblemático del Poblenou industrial dedicado durante medio siglo a la confección de tejidos y que en la actualidad se está restaurando bajo la dirección de la Universidad de Barcelona.

Más tarde se atraviesa la avenida de la Diagonal para ir hacia el Parque del Centro de Poblenou, antiguo recinto fabril convertido en la actualidad en un lugar de diseño artístico (las vistas son los nuevos edificios de Chipperfield). Se trata de 55.000 metros cuadrados de espacio verde, obra de la arquitectura de diseño de Jean Nouvel que fue inaugurada en abril de 2008. Aunque también se ponen de manifiesto las nuevas tecnologías de la información y la comunicación (por ejemplo, en el Pozo del Mundo), se hace alusión al uso y a la reapropiación vecinal, desde la organización de asociaciones de sardanas hasta la celebración de numerosas calçotades.

Cruzando por la antigua fábrica Hispano Olivetti, atravesamos la calle Bilbao y el camino antiguo de Valencia y nos dirigimos a Can Felipa (calle Pallars, 277), convertido en centro cívico y en otro de los núcleos de movilización vecinal en torno al patrimonio industrial, así como en un símbolo de la reproducción de la memoria del barrio. Posteriormente, la ruta se dirige hacia Can Saladrigas — donde se iniciaba el primer itinerario-, edificio constituido en centro de la cultura industrial de Barcelona y también otro de los elementos esenciales de la reivindicación patrimonial del barrio.

Continuando a lo largo de la rambla del Poblenou se llega a la calle del Taulat, antiguo límite del barrio pesquero de Poblenou en cuyo espacio se realizaron múltiples construcciones de barracas y chabolas y donde actualmente se encuentran solares abandonados. En este punto se insiste en el carácter originario de la zona (el primer entorno construido por pescadores), a diferencia 
Figura 6. Casas bajas en la calle del Taulat

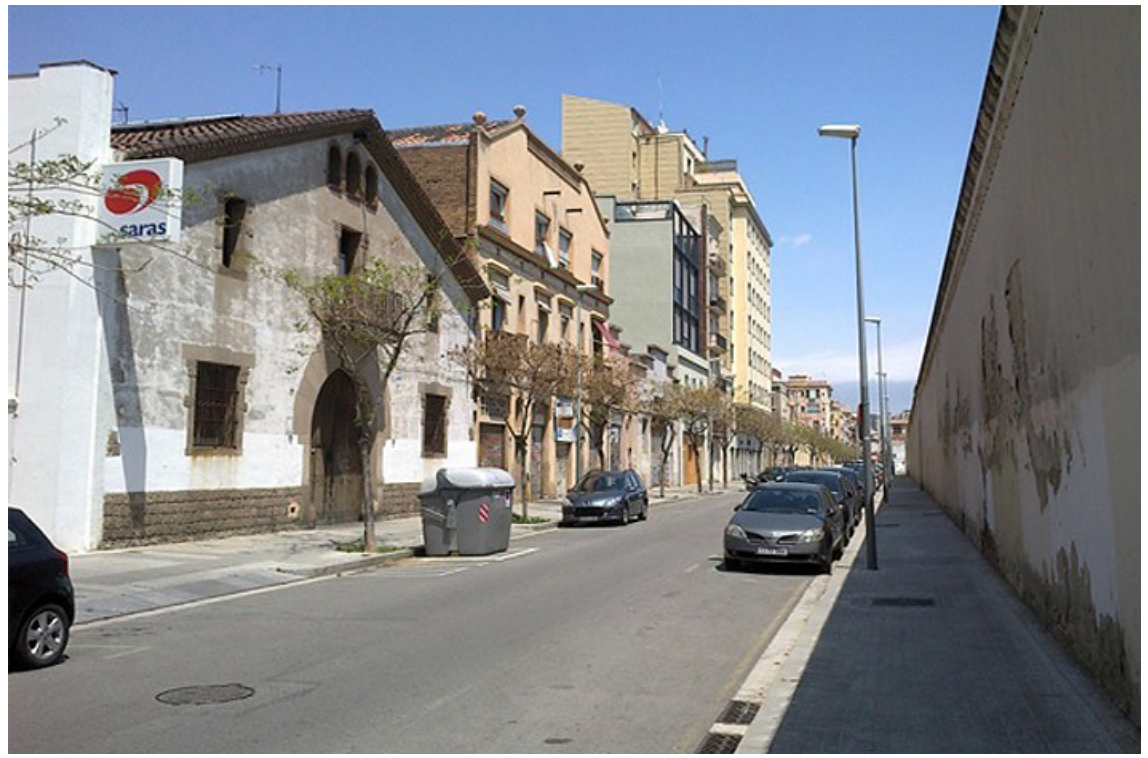

Fuente: autores.

Figura 7. Itinerario vecinal de Poblenou en verde. Itinerario organizado por $22 @$ en rojo

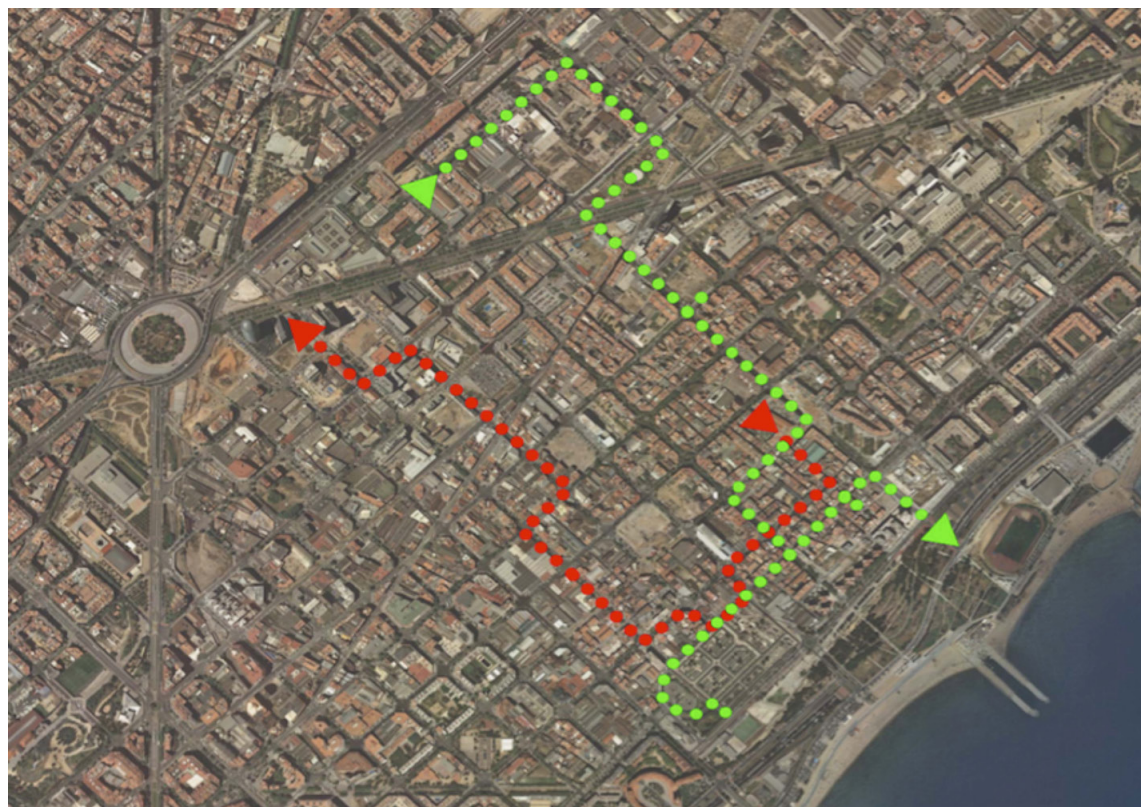

Fuente: elaboración propia a partir de PNOA del (C) Instituto Geográfico Nacional. 
del resto de bloques de viviendas, como muestran las diferencias en la trama urbana. El recorrido se dirige a lo largo del Taulat hacia el cementerio de Poblenou y el Casal del Barri de la Vila Olímpica i del Poblenou, situado en el antiguo complejo fabril Can Gili Nou.

Volviendo por la calle del Taulat en dirección contraria se confirma que la edificación cambia a lo largo de la misma, puesto que se derrumbaron casas de una o dos alturas de un barrio típico de pescadores (figura 7). Después de pasar por la calle Topete, el itinerario se dirige hacia la plaza Prim, antiguo centro histórico de Poblenou y lugar de celebraciones en las fiestas de mayo, la Fiesta Mayor de septiembre y la llegada de la Cursa de Sant Pollastre. El itinerario se detiene justo antes de cruzar la calle en dirección a la playa del Bogatell, para recordar que enfrente mismo, donde se levantó el recinto del Fórum de las Culturas, se encuentra el Campo de la Bota, lugar de memoria de los fusilados durante la Guerra Civil y la dictadura franquista y donde fueron asesinadas cerca de dos mil personas.

\subsection{La trialéctica en clave de itinerarios barriales}

Ambos itinerarios constituyen dos tipos de práctica espacial a través de los cuales se proyectan diferentes formas de concebir y de vivir el espacio de Poblenou, lo que produce una contestación y una negociación entre modos opuestos de diseñar y de practicar espacialmente la memoria barrial y genera una trialéctica espacial.

El primer itinerario apelaba a la consideración de las nuevas industrias y al vínculo entre la sostenibilidad, las actividades @ y la limpieza en la accesibilidad y la movilidad en dicha zona en referencia a la estructuración de dicho espacio ${ }^{11}$. Asimismo, la Administración local reformuló las espacialidades «oficiales», ya que el 22@ no agrupaba ni Poblenou ni Sant Martí, sino que constituía una zona distinta definida por las nuevas inversiones en innovación y economía del conocimiento (Dot Jutglà et al., 2010b; Martí-Costa y Pradel i Miquel, 2012; D’Ovidio y Pradel, 2013). Ello implicó en la práctica una nueva delimitación alrededor de seis áreas redefinidas donde se emplazaban los clústeres implantados en los ejes de Llull Pujades Llevant, Perú-Pere IV, Parc Diagonal, Campus Audiovisual, Parc Central Eix Llacuna y Llull Pujades Ponent (Ayuntamiento de Barcelona, 2005: 14).

Además, atendiendo al recorrido, el itinerario realizado va deteniéndose junto a edificios rehabilitados que han sido renovados e incluidos dentro de la economía creativa, bien por su reconocimiento como parte del patrimonio industrial, bien por la transformación de actividades productivas previamente diseñadas y planificadas como parte de esas representaciones expertas o «auto-

11. En la memoria del Plan Especial de Infraestructuras de Poblenou (Ayuntamiento de Barcelona, 2000), aparte del énfasis dado a la accesibilidad, la movilidad o la limpieza, se hace hincapié en su coordinación con el tratamiento de residuos, el ciclo del agua, los sistemas de energía y las telecomunicaciones en clave @. 
rizadas» del espacio. El recorrido hace hincapié en los edificios y en las tramas urbanas vinculadas al 22@ o, en su defecto, a aquellas que desligan el paisaje industrial con el Poblenou como barrio, como sucede con la plaza del barrio de La Plata o con el territorio relacionado con la memoria de la lucha vecinal, como implica dejar fuera del itinerario la parte norte de la Diagonal, Can Ricart, La Escocesa o algunos recintos fabriles situados en la calle de Pere IV, escenarios de importantes reivindicaciones populares. Ello está en consonancia con esa idea del 22@ como un macroproyecto que influirá y modificará no solo los espacios sobre los que se desarrolla, sino también otros ámbitos e incluso los núcleos estructurales de la ciudad, puesto que se trata de un cambio inserto en el papel reforzado del planeamiento urbanístico reconocido o en las dinámicas de diferenciación zonal y en la reestructuración de sectores urbanos (figura 5).

Considerando las representaciones del espacio como la extensión concebida que busca imponer una determinada forma de mirar, de pensar y de practicar el lugar desde una normatividad supuestamente objetiva, esta reestructuración del espacio local, concebida y abstracta, diseñada desde las instituciones y puesta en práctica, enseñada y proyectada mediante el itinerario anterior, podría estar configurando un modelo de ciudad según el cual imperan la economía creativa, el paisaje urbano, el patrimonio arquitectónico y monumental, la producción cultural, la innovación, las nuevas tecnologías o la calidad de vida ${ }^{12}$ por encima de otros referentes, imaginarios y usos del espacio público urbano. Como puede verse, si se analiza el mapa de los nodos de renovación del 22@ y las áreas de influencia del Plan Especial de Infraestructuras de Poblenou (figura 5), el itinerario escogido por el Centro de Cultura Contemporánea de Barcelona se acerca bastante más a estas innovadoras "representaciones del espacio» de Poblenou que a las delimitaciones establecidas en cartografías vecinales o incluso en la anterior división administrativa del barrio (figura 1), especialmente si se atiende a los lugares en que se va deteniendo el mismo, así como el punto de finalización del recorrido, justo en la Diagonal (figura 7).

Por su parte, el segundo recorrido pone el énfasis en lugares distintos a los del primero - fundamentalmente en los antiguos grandes centros fabriles-, resaltando el valor que tienen para la memoria del barrio con independencia de su uso o de su restauración, porque, aunque también se recorren centros cívicos y de producción artística, lo principal es remarcar si estaban dentro de las demandas principales del barrio y en aquellos sitios inscritos en la memoria histórica del mismo (figura 6).

De esta forma, se trata de un itinerario mar-montaña distinto al de la avenida Diagonal o al territorio diseñado por el 22@, en consonancia con las reclamaciones vinculadas a diferentes movimientos asociativos del barrio, que

12. Artículo 1 del Plan especial de ordenación de establecimientos comerciales destinados a la venta de artículos de recuerdos o souvenirs de la ciudad de Barcelona, artículos 4-5 de la Ordenanza de los usos del paisaje urbano de la ciudad de Barcelona, artículos 30-32 de la modificación del Plan General metropolitano del plan especial de protección del patrimonio arquitectónico histórico-artístico de la ciudad de Barcelona, distrito de Sant Martí (noviembre de 2006). 
las consideran «las dinámicas urbanas que funcionan en términos de interacción social y movimiento de gente» ${ }^{13}$. En este sentido, el trayecto pasa por sitios restaurados o por «viejos lugares», pero que implican algo respecto a la memoria vecinal, como muestra el significativo ejemplo del comienzo cerca de Can Ricart (foco de mayor movilización vecinal de Poblenou) y de la conclusión en la plaza Prim o de los Pescadores, donde actualmente se producen los recordatorios de pescadores y el recuerdo del viejo pueblo pesquero que fue Poblenou (figura 7). Teniendo en cuenta que los lugares de representación constituirían ese ámbito desde el cual se podría configurar un punto de resistencia a la producción del espacio urbano, este recorrido evoca y configura un entorno de representación que recrea el ambiente vivido alrededor del barrio como lugar de experiencia cotidiana que contestaría a las representaciones espaciales articuladas desde el 22@.

\section{Conclusiones: itinerarios patrimoniales y trialéctica barrial}

Las disputas por los itinerarios industriales de Poblenou obedecían a un interés por delimitar no el recorrido en sí, sino la legitimidad histórica patrimonial del legado fabril y, con ello, los lugares reconocidos dentro de la misma en torno a un espacio público concreto desde distintas formas de imaginarlo, proyectarlo y practicarlo, bien fuese a partir de representaciones concebidas y promovidas desde las instituciones locales, bien desde prácticas de socialización espacial aprendidas y difundidas por los movimientos vecinales que vinculaban el itinerario al patrimonio industrial local. Estos recorridos como prácticas espaciales dibujan la disputa entre un espacio concebido que trata de adecuar la imagen y el significado de Poblenou a ciertos objetivos establecidos por la planificación experta y un espacio vivido que imagina su propio territorio desde la experiencia diaria del mismo, sus símbolos y significados.

En ambos casos, los itinerarios se erigen en prácticas espaciales articuladas para establecer límites sociales e imaginarios geográficos en un sentido triple: en primer lugar, porque el recorrido establece lo que está dentro y fuera del ámbito «representado», sea el barrio en sentido tradicional (Poblenou) o el distrito barrio que se intenta proyectar desde las representaciones institucionales de ese espacio público (el 22@). En segundo lugar, porque eso a su vez articula los referentes del propio barrio: en el caso del 22@, el itinerario se detiene en edificios donde se practican actividades productivas creativas y que suponen iconos representativos conforme a imaginarios globales o a formas de producción global a través de una representación del Poblenou basada en su simbolismo como lugar histórico de producción, aunque mediante edificaciones aisladas que rompen con la trama urbana tradicional en torno a la socialización cotidiana del barrio. Por el contrario, en el otro recorrido, la imaginación geográfica articulada se retrae al cariz barrial en toda la extensión de la memoria vecinal, desde una historia pesquera hasta la reciente recuperación

13. Informante clave en el movimiento vecinal de Poblenou, entrevista personal. 
patrimonial industrial. En este segundo aspecto podríamos decir que se trata de una oposición entre formas de entender, concebir y representar el patrimonio, entendido en el primer caso como algo eminentemente económico y encarnado en antiguos edificios fabriles restaurados, y apreciado en el segundo caso alrededor de espacios sociales cuyo elemento legitimador y que los define es la memoria vecinal y la socialización espacial barrial. Asimismo, el recorrido rompe de alguna manera la división planteada por el primer itinerario y por el trayecto seguido a lo largo de la Diagonal, en aras de reunificar las prácticas vecinales y resignificarlas en clave de memoria de los lugares patrimoniales, alzándose por encima de un potencial aislamiento promovido por la planificación urbanística y naturalizado por los itinerarios que se enfatizan en el 22@ o en la parte sur de la Diagonal.

Por último, estos recorridos son utilizados como herramientas de oposición, disputa y definición de los espacios legítimos de referencia y, en última instancia, de los lugares o de los referentes sociales a nivel cotidiano. Son prácticas en conflicto, cuya particularidad reclama su propio ámbito y en cuya oposición encontramos el uso del itinerario para la apropiación y la definición del patrimonio industrial, así como para la resignificación de los ámbitos y de los grupos sociales de referencia en el espacio urbano barcelonés. En un caso irrumpen nuevas formas de espacialidad urbana en consonancia con representaciones de la zona que apelan a nuevas cartografías institucionales del espacio público, a escalas globales del imaginario urbano barcelonés o de la economía creativa y del conocimiento (22@y los clústeres empresariales), mientras en el otro caso aparece el ámbito tradicional, que impele a la memoria vecinal, a obreros y pescadores, al patrimonio industrial o al lugar de socialización y contestación cotidiana que supone el barrio desde su articulación como contraespacio. En última instancia, la existencia de un tipo de itinerario trazado a instancias de las instituciones y en consonancia con las representaciones hegemónicas del espacio público barcelonés no solo no silencia la configuración de otros recorridos desde la práctica del barrio como ámbito de representación, sino que, en este caso, implica su articulación consciente como forma de contestación y como reivindicación de otro Poblenou, lo que verifica la pertinencia de la trialéctica espacial como herramienta teórica en la constante producción y contestación del espacio urbano.

\section{Referencias bibliográficas}

AVV Poblenou (2004). Els carrers del Poblenou. Barcelona: Arxiu Històric del Poblenou.

AAVV (2004). La otra cara del Fòrum de les Cultures, S. A. Barcelona: Bellaterra.

- (2011). "Economía del conocimiento y territorio». Revista Econòmica de Catalunya, 64.

Alabart, A. (1998). "Els moviments socials urbans a Catalunya». Revista Catalana de Sociologia, 7 (98), 9-28.

Alfama, E. (coord.) (2007). Per una nova cultura del territori?: Mobilitzacions i conflictes territorials. Barcelona: Icaria. 
Ayuntamiento de Barcelona (2000). Plan Especial de Infraestructuras de Poblenou.

- (2005). Estado de ejecución del 22@ en torno a la Modificación del plan general metropolitano en el ámbito del casco antiguo de Poblenou, distrito de Sant Martí.

- (2008). Estado de ejecución del 22@ en torno a la Modificación del plan general metropolitano en el ámbito del casco antiguo de Poblenou, distrito de Sant Martí.

- (2009). Estado de ejecución del 22@ en torno a la Modificación del plan general metropolitano en el ámbito del casco antiguo de Poblenou, distrito de Sant Martí (diciembre).

- (2010a). Estado de ejecución del 22@en torno a la Modificación del plan general metropolitano en el ámbito del casco antiguo de Poblenou, distrito de Sant Martí.

- (2010b). Modificación Puntual del Plan General Metropolitano en el ámbito del casco antiguo del Poblenou (aprobado el 26 de febrero de 2010).

BAER, A. (2006). Holocausto: Recuerdo y representación. Madrid: Losada.

BALIBREA, M. (2007). «La marca y el pasado: Estrategias de lucha por el espacio social en la Barcelona postindustrial». En: Yproductions (ed.). Producta50: Una introducción a las relaciones entre economía y cultura. Barcelona: Generalitat de Catalunya, 20-35.

BENACH, N. y AlBET, A. (2010). Edward Soja: La perspectiva posmoderna de un geógrafo radical. Barcelona: Icaria.

Bordetas, I. (2009). Del suburbio al barrio: Los orígenes del movimiento vecinal en Barcelona. Tesina de doctorado del Programa Historia Comparada, Política, Social y Cultural de la UAB (septiembre).

- (2010). «De la supervivència a la resistència: La gestació del moviment veïnal a la Catalunya franquista». En: Molinero, C. e YsÂs, Pere (coords.). Construint la ciutat democrática: El moviment veïnal durant el tardofranquisme i la transició. Barcelona: Icaria, 25-112.

CASELlAS, A. (2009). «Barcelona's urban landscape: The historical making of a tourist product». Journal of Urban History, 35 (6), 815-832. <https://doi.org/10.1177/0096144209339557>

Casellas, A.; Dot, E. y Pallarès-Barberà, M. (2010). «Creación de imagen, visibilidad y turismo como estrategias de crecimiento económico de la ciudad». Finisterra, XLV (90), 153-172. <https://doi.org/10.18055/Finis1345>

- (2012). "Artists, Cultural Gentrification and Public Policy». Urbani Izziv, 23, 104-114. Recuperado de <10.5379/urbani-izziv-en-2012-23-supplement-1-010>.

Casellas, A. y Pallarès-BarberÀ, M. (2009). «Public-sector intervention in embodying the new economy in inner urban areas: The Barcelona experience». Urban Studies, 46 (5/6), 1137-1155.

<https://doi.org/10.1177/0042098009103858>

CHARnock, G. y Ribera-Fumaz, R. (2011). «A new space for knowledge and people?: Henri Lefebvre, representations of space and the production of 22@ Barcelona». Urban Development and Planning D: Society and Space, 29 (4), 613-632. $<$ https://doi.org/10.1068/d17009>

Checa, M. (2002). Poblenou, la fábrica de Barcelona. Barcelona: Ajuntament de Barcelona.

Checa Artasu, M. M. (2007). «Geografías para el patrimonio industrial en España: El caso de Barcelona». Scripta Nova: Revista Electrónica de Geografía y Ciencias Sociales. Universidad de Barcelona, XI, 245 (32). <http://dx.doi.org/10.1344/sn2007.11.1359> 
- (2008). «Una herramienta para la planificación urbana. La documentación del patrimonio. El caso de Barcelona (España). Scripta Nova: Revista Electrónica de Geografia y Ciencias Sociales, XII, 270 (141). <http://dx.doi.org/10.1344/sn2008.12.1565>

Chouliaraki, L. y Fairclough, N. (1999). Discourse in Late Modernity: Rethinking critical discourse analysis. Edimburgo: Edinburgh University Press.

- (2000). «Language and power in Bourdieu: On Hasan's The Disempowerment game». Linguistics and Education, 10 (4), 399-409. <https://doi.org/10.1016/S0898-5898(00)00018-8>

Clark, G. (2011). "¿Es necesario que las ciudades globales tengan distritos del conocimiento?: Observaciones sobre el 22@ en Barcelona y sus homólogos».Revista Econòmica de Catalunya, 64 (octubre), 158-174.

Clarós S. et al. (2005). "Proposta de pla de patrimoni industrial de Barcelona». Revista Bibliográfica de Geografía y Ciencias Sociales, X (581).

DEgen, M. (2008). Sensing cities: Regenerating public life in Barcelona and Manchester. Milton Park-Nueva York: Routledge.

- (2010). "Consuming urban rhythms: Let's ravalejar». En: EDENSOR, T. (ed.). Geographies of rhythm. Aldershot: Ashgate.

Degen, M. y GARCÍA, M. (2008). La metaciudad: Barcelona, transformación de una metrópolis. Barcelona: Anthropos.

- (2012). "The transformation of the Barcelona Model: An analysis of culture, urban regeneration and governance». International Journal of Urban and Regional Research, 36 (5), 1022-1038. <https://doi.org/10.1111/j.1468-2427.2012.01152.x>

Domingo, M. y Bonet, M. R. (1998). «Urbanisme i participació». Revista Catalana de Sociologia, 7, 73-89.

Dot Jutglà, E.; Casellas, A. y Pallarès-Barberà, M. (2010a). "L'ambigüitat de la producció intensiva en coneixement: El nou espai econòmic del Poblenou». Documents d'Anàlisi Geogràfica, 56 (3), 389-408.

- (2010b). «Gentrificación productiva en Barcelona: Efectos del nuevo espacio económico». Actas de las IV Jornadas de Geografía Económica. Grupo de Geografía Económica de la Asociación de Geógrafos Españoles, León, 1 y 2 de julio de 2010, $1-13$.

- (2012). "Gentrificació productiva, desindustrialització i relocalització industrial». Treballs de la Societat Catalana de Geografia, 73, 27-52. Recuperado de <http://revistes.iec.cat/index.php/TSCG/article/view/63642/63570>.

Dot Jutglà, E.; Pallarès-Barberà, M. y Casellas, A. (2011). «La Barcelona emprendedora: El Plan 22@Barcelona y los agentes de cambio». En: GONZÁLEZ, Vicente y Marco, Juan Antonio (ed.). Urbanismo expansivo: De la utopía a la realidad. Alicante: Universitat d'Alacant, 217-228.

Dot Jutglà, E.; Pallarès-Barberà, M. y Vera Martín, A. (2009). «El 22@Barcelona o el liderazgo del espacio urbano: La economía del conocimiento en la Barcelona del siglo XXI». En: Feria TOribio, J. M.; García García, A. y Ojeda Rivera, J. A. (coord.). Localización: Territorios, sociedades y politicas. Sevilla: Universidad Pablo de Olavide, 525-536.

D'Ovidio, M. y Pradel, M. (2013). «Social innovation and institutionalisation in the cognitive-cultural economy: Two contrasting experiences from Southern Europe». Cities, 33, 69-76.

<https://doi.org/10.1016/j.cities.2012.07.002> 
Eizaguirre, S.; Pradel, M.; Terrones, A.; Martínez-Celorrio, X. y García, M. (2012). "Multilevel governance and social cohesion: Bringing back conflict in citizenship practices». Urban Studies, 49 (9), 1999-2016. <https://doi.org/10.1177/0042098012444890>

Elden, S. (2004). Understanding Henri Lefebvre: Theory and the Possible. Londres: Continuum.

FAVB (2008). «La Barcelona dels barris». Quaderns de Carrer, 3. Barcelona: FAVB.

- (2010). «1970-2010: 40 anys d'acció veïnal». Quaderns de Carrer, 5. Barcelona: FAVB.

FERnÁndez, M. y TATJer, M. M. (2005). «La ciudad como taller». Íber: Didáctica de las Ciencias Sociales, Geografía e Historia, 43, 58-66.

GÁrate NAVArRete, V. (2011). El modelo Barcelona de espacio público y diseño urbano: Las chimeneas industriales como elemento de arte público. Recuperado de <http:// hdl.handle.net/2445/17382> [Fecha de consulta: 13/03/2012].

GonZÁlez, S. (2011). «Bilbao and Barcelona "in motion": How urban regeneration "models" travel and mutate in the global flows of policy tourism». Urban Studies, 48 (7), 1397-1418. <https://doi.org/10.1177/0042098010374510>

GoOneWARdena, K. y Kipfer, S. et al. (2008). Space, difference, everyday life: Reading Henri Lefebvre. Nueva York: Routledge.

Guillot, S. (2004). El proyecto 22@Barcelona: Estado de ejecución y estudio comparativo con experiencias similares en Europa. Barcelona: Aula Barcelona.

HaY, I. (2010). Qualitative research methods in human Geography. Ontario: Oxford University Press.

HiernauX-Nicolás, D. (2004). «Henri Lefebvre: Del espacio absoluto al espacio diferencial». Revista Veredas, 8, 11-25.

Howarth, D. (2005). "Aplicando la Teoría del discurso: El método de la articulación». Studia Politicae, 5 (otoño), 37-88.

Johnston, R. J.; Gregory, D. y SMith, D. M. (2000). Diccionario Akal de Geografía Humana. Madrid: Akal.

Lefebvre, H. (1974). La producción de espacio. Madrid: Capitán Swing, 2013.

- (1976). Espacio y política: El derecho a la ciudad II. Barcelona: Península.

- (1991a). The critique of everyday life. Londres: Verso.

- (1991b). The production of space. Oxford: Blackwell.

LeIva, E.; Miró, I. y URBAnO, X. (2007). De la protesta al contrapoder: Nous protagonismes socials en la Barcelona metropolitana. Barcelona: Virus.

López, A.; Romaní, A.; Sagarra, R. y Piqué, J. M. (2011). «22@Barcelona: Exportando el modelo». Revista Econòmica de Catalunya, 64 (octubre), 110120.

Marrero Guillamón, I. (2003). «¿Del Manchester catalán al Soho barcelonés?: La renovación del Poblenou en Barcelona y la cuestión de la vivienda». Scripta Nova: Revista Electrónica de Geografia y Ciencias Sociales, VII, 146 (137). <http://dx.doi.org/10.1344/sn2003.7.776>

Marsh, D. y Stoker, G. (1997). Teoría y métodos de la ciencia política. Madrid: Alianza.

Martí i Costa, M. y Bonet i Martí, J. (2008). «Los movimientos urbanos: De la identidad a la globalidad». Scripta Nova: Revista Electrónica de Geografía y Ciencias Sociales, XII, 270 (121).

<http://dx.doi.org/10.1344/sn2008.12.1544> 
Martí-Costa, M. y Pradel i Miquel, M. (2012). «The knowledge city against urban creativity?: Artists' workshops and urban regeneration in Barcelona». European Urban and Regional Studies, 19 (1), 92-108. <https://doi.org/10.1177/0969776411422481>

McNeILl, D. (2007). «Hotel Barcelona». En: Yproductions (ed.). Producta50: Una introducción a las relaciones entre economía y cultura. Barcelona: Generalitat de Catalunya, 144-155.

Molinero, C. e YsÂs, P. (coords.) (2010). Construint la ciutat democràtica: El moviment veïnal durant el tardofranquisme i la transició. Barcelona: Icaria.

MuÑoz, F. (2008). UrBANALización: Paisajes comunes, lugares globales. Barcelona: Gustavo Gili.

- (2010). «Contra la urbanalització: De la ciutat post-it a la ciutat pòsit». Revista del Centre d'Estudis Jordi Pujol, 12, 189-200.

Muxí, Z. y BORJA, J. (2003). Urbanismo del siglo XXI: Bilbao, Madrid, Valencia, Barcelona. Barcelona: Edicions de la UPC.

Oliva, A. (2003). El districte d'activitats 22@bcn. Barcelona: Aula Barcelona / Publicacions de la Universitat de Barcelona.

OSLENDER, U. (2010). «La búsqueda de un contra-espacio: ¿Hacia territorialidades alternativas o cooptación por el poder dominante?». Geopolitica(s), 1, 95-114.

Pareja-Eastway, M. y Pradel, M. (2010). "New economy, new governance approaches?: Fostering creativity and knowledge in the Barcelona Metropolitan Region». Creatives Industries Journal, 3 (1), 29-46. <https://doi.org/10.1386/cij.3.1.29_1>

Pendlebury, J.; Short, M. y While, A. (2009). «Urban World Heritage Sites and the Problem of Authenticity». Cities, 26 (6), 349-358. <https://doi.org/10.1016/j.cities.2009.09.003>

PiQuÉ, J. M. (2008). «El projecte 22@ Barcelona: Present i futur». Informe Anual de la Província de Barcelona 2008. Barcelona: Cambra de Comerç de Barcelona, 239-252.

Rojas, J.; Pellicer, I.; SANTORO, V. y ViVAS, P. (2007). «@City: lecturas tecnológicas de Barcelona». Athenea Digital, 11, 114-131. <https://doi.org/10.5565/rev/athenead/v0n11.384>

Rose, G. (2014). The question of method: Practice, reflexivity and critique in visual culture studies. Recuperado de <www.academia.eu> [Fecha de consulta: 08/01/2015].

SCHMID, C. (2008). "Henri's Lefebvre theory of the production of space: Towards a three-dimensional dialectic». En: Goonewardena, K.; Kipfer, S.; Milgrom, R. y SCHMID, C. (eds.). Space, difference, everyday life: Reading Henri Lefebvre. Nueva York: Routledge, 27-45. <https://doi.org/10.1111/j.1745-7939.2009.01167_6.x>

SojA, E. (1996). Thirdspace: Journeys to Los Angeles and other real and imagined places. Malden, Massachusetts: Blackwell Publishers Inc.

Subirats, J. (2012). «¿Nuevas políticas urbanas?: Ocho argumentos a favor de una reconsideración de las políticas urbanas en España en un entorno social de creciente complejidad». En: Montaner, J. Ma . y Subirats, J. (coords.). Repensar las politicas urbanas: Apuntes para la agenda urbana. Barcelona: Diputació de Barcelona, 220-236.

TAtjer, M. M. (2008). «El patrimonio industrial de Barcelona entre la destrucción y la conservación, 1999-2008». Scripta Nova: Revista Electrónica de Geografía y Ciencias Sociales, XII (270), 140. <http://dx.doi.org/10.1344/sn2008.12.1564> 
TAtjer, M. M. y Vilanova, A. (2002). La ciutat de les fabriques: Itineraris industrials de Sant Martí. Barcelona: Districte de Sant Martí.

TuAn, Y. F. (1977). Space and place: The perspective of experience. Mineápolis: University of Minnesota Press.

UTE (2004). Barcelona: marca registrada: Un model per desarmar. Barcelona: Virus.

VALERA, S. (2009). «El Poblenou barcelonés como barrio artístico». En: LORENTE, J. P. et al. (eds.). Arte en el espacio público: Barrios artísticos y revitalización urbana. Zaragoza: Prensas Universitarias de Zaragoza.

Vera Martín, A.; Pallarès Barberà, M. y Tulla Pujol, A. (2009). «La nueva economía y los espacios industriales tradicionales: El caso del 22@ Barcelona». Barcelona: Universitat de Barcelona.

VIEJO-Rose, D. (2013). «Patrimonio cultural armado: La violencia cultural y simbólica». En: OrTIZ, Carmen (ed.). Lugares de represión, paisajes de la memoria: La cárcel de Carabanchel. Madrid: Los Libros de la Catarata, 21-27.

WaITT, G. (2000). «Consuming Heritage: Perceived Historical Authenticity». Annals of Tourism Research, 27 (4), 835-62. <https://doi.org/10.1016/S0160-7383(99)00115-2>

Yproductions (ed.). Producta50: Una introducción a las relaciones entre economía y cultura. Barcelona: Generalitat de Catalunya. 